\title{
ANALISIS PENGENDALIAN PERSEDIAAN BAHAN BAKU BERDASARKAN METODE ECONOMIC ORDER QUANTITY (EOQ) PADA PERUSAHAAN OBOR MAS (ROTI AMIN) BANDAR LAMPUNG
}

\author{
Iskandar Ali Alam \\ Fakultas Ekonomi Universitas Bandar Lampung \\ Jl. Z.A Pagar Alam No. 26 Labuhan Ratu Bandar \\ Lampung 35142 Telp. 0721-701979 Fax 0721701463 \\ Vera Anggraini \\ Fakultas Ekonomi Universitas Bandar Lampung \\ J1. Z.A Pagar Alam No. 26 Labuhan Ratu Bandar \\ Lampung 35142 Telp. 0721-701979 Fax 0721701463 \\ email: vera.15011016@student.ubl.ac.id
}

\begin{abstract}
Every company has the main goal of obtaining optimal profits and overseeing the company's progress and the development of the company. One way for companies to obtain optimal profits is to implement a management policy by calculating optimal inventory, one of which is the supply of raw materials. Optimal inventory of raw materials is an important factor in the process of smooth production of a company. These raw materials can be controlled using the Economic Order Quantity (EOQ) method which has a better level of calculation accuracy than conventional methods. This research has a type of quantitative research with a design in the form of search research. The research design used is quantitative research which has the aim to explore more about the use of the Economic Order Quantity (EOQ) method in controlling the raw materials of the Torch Mas Company (Roti Amin) Bandar Lampung. The object of this research is the number of purchases, the amount of inventory, the amount of usage of raw materials used in the production process, as well as the ordering costs and storage costs of raw materials. Which aims to find optimal raw material purchases, optimal purchase frequency, safety stock, reorder point, and efficient total inventory costs. The results showed that the optimal inventory of wheat flour using the EOQ method was $3.118 \mathrm{~kg}$ with a frequency of purchases of 21 times, Safety Stock of 1,290 kg and ROP when the raw material was stocked for 1,521 $\mathrm{kg}$ with TIC Rp 3.803.993. The conclusion of this study is that the calculation using the EOQ method on wheat flour raw material is more efficient than the conventional method. The recommended advice for the management of the Torch Corporation (Roti Amin) Bandar Lampung is to use the EOQ method in the process of controlling the company's raw materials.
\end{abstract}

Keywords: Economic Order Quantity (EOQ), Raw Material Inventory, Safety Stock (SS), Reorder Point (ROP), Total Inventory Cost (TIC)

Abstrak
Setiap perusahaan memiliki tujuan utama yaitu memperoleh laba yang optimal dan mengawasi berjalanya perusahaan serta berkembangnya perusahaan. Salah satu cara agar perusahaan memperoleh laba yang optimal adalah menerapkan suatu kebijakan manajemen dengan memperhitungkan persediaan yang optimal salah satunya yaitu persediaan bahan baku. Persediaan bahan baku yang optimal merupakan faktor penting dalam proses kelancaran produksi pada suatu perusahaan. Bahan baku ini dapat dikendalikan dengan menggunakan metode Economic Order Quantity (EOQ) yang memilki tingkat keakuratan perhitungan yang lebih baik dibandingkan dengan metode konvensional.Penelitian ini memiliki jenis penelitian kuantitaif dengan desain berupa penelitian penelusuran. Desain penelitian yang digunakan adalah peneletian kuantitatif yang memiliki tujuan untuk mengakaji lebih dalam tentang penggunaan metode Economic Order Quantity (EOQ) dalam mengendalikan bahan baku Perusahaan Obor Mas (Roti Amin) Bandar Lampung. Objek penelitian ini adalah jumlah pembelian, jumlah persediaan, jumlah pemakaian bahan baku yang digunakan dalam proses produksi, serta biaya pemesanan dan biaya penyimpanan bahan baku. Yang bertujuan mencari pembelian bahan baku yang optimal, frekuensi pembelian yang optimal, persediaan pengaman Safety Stock, titik pemesanan kembali Reorder Point, dan total biaya persediaan yang efisien.Hasil penelitian didapatkan persediaan optimal bahan baku tepung terigu menggunakan metode EOQ sebesar $3.118 \mathrm{~kg}$ dengan frekuensi pembelian sebanyak $21 \mathrm{kali}$, Safety Stock sebesar $1.290 \mathrm{~kg}$ dan ROP dilakukan pada saat bahan baku digudang sebesar $1.521 \mathrm{~kg}$ dengan 
TIC Rp 3.803.993. Kesimpulan dari penelitian ini adalah perhitungan menggunakan metode EOQ pada bahan baku tepung terigu lebih efisien dibandingkan dengan metode konvensional. Saran yang dianjurkan bagi manajemen Perusahaan Obor Mas (Roti Amin) Bandar Lampung adalah untuk menggunakan metode EOQ dalam proses pengendalian bahan baku perusahaan.

Kata kunci : Economic Order Quantity (EOQ), Persediaan Bahan Baku, Safety Stock (SS), Reorder Point (ROP), Total Inventory Cost (TIC). 


\section{PENDAHULUAN}

Seiring dengan kemajuan teknologi dan berkembangnya ilmu pengetahuan tentunya persaingan antar perusahaan di Indonesia semakin meningkat. perusahaan memiliki tujuan utama yaitu memperoleh laba yang optimal dan mengawasi berjalanya perusahaan serta berkembangnya perusahaan.Dalam pencapaian tujuan tersebut perusahaan akan mengalami kendala dan masalah tertentu sehingga perusahaan harus memiliki manajemen yang baik. Pada dasarnya manajemen yang baik harus memiliki fungsi yang sangat penting dalam perusahaan guna melakukan pemilihan keputusan serta sebagai control dalam kegiatan perusahaan supaya berjalan secara efektif dan perusahaan mampu memperoleh laba yang optimal. Salah satu cara agar perusahaan memperoleh laba yang optimal adalah menerapkan suatu kebijakan manajemen dengan memperhitungkan persediaan yang optimal.

Perusahaan Obor Mas adalah sebuah perusahaan yang bergerak dibidang pembuatan roti. Perusahaan ini memiliki bahan baku utama yaitu tepung terigu. Dalam kegiatannya, perusahaan membuat kebijakan mengenai pengelolaan persediaan dengan cara konvensional, yaitu melakukan pembeliaan terus menerus tanpa memperkirakan kebutuhan produksi. Hal ini untuk mengantisipasi kekurangan bahan atau terlambatnya pengiriman. Perusahaan harus bisa merencanakan persediaan bahan baku tersebut secara tepat. Disamping agar proses produksi tetap jalan, juga agar ketersediaan bahan baku bisa terus ada kapan saja. Perusahaan Obor Mas melakukan pembelian persediaan bahan baku dengan waktu tunggu 1 hari. Berikut data pembeliaan dan pemakaian bahan baku tepung terigu tahun 2017.

Tabel 1 Pembelian dan Pemakaian Bahan Baku Tepung Terigu pada Perusahaan Obor Mas (Roti Amin) Tahun 2017

\begin{tabular}{|c|l|c|c|c|}
\hline No & \multicolumn{1}{|c|}{ Bulan } & Pembeliaan $(\mathrm{Kg})$ & Pemakaian $(\mathrm{Kg})$ & Pembelian-Pemakaian $(\mathrm{Kg})$ \\
\hline 1 & Januari & 5.800 & 4.040 & 760 \\
\hline 2 & Februari & 5.200 & 5.400 & $(200)$ \\
\hline 3 & Maret & 5.400 & 5.760 & $(360)$ \\
\hline 4 & April & 5.700 & 4.320 & $(200)$ \\
\hline 5 & Mei & 5.200 & 5.400 & $(720)$ \\
\hline 6 & Juni & 5.400 & 6.120 & $(940)$ \\
\hline 7 & Juli & 5.900 & 6.840 & 140 \\
\hline 8 & Agustus & 5.900 & 5.760 & 1.220 \\
\hline 9 & September & 5.900 & 4.680 & 200 \\
\hline 10 & Oktober & 5.000 & 6.480 & 400 \\
\hline 11 & November & 5.600 & 5.400 & 200 \\
\hline 12 & Desember & 5.800 & 5.400 & \\
\hline \multicolumn{2}{r|}{ Jumlah } & 66.800 & 66.600 & 5.550 \\
\hline \multicolumn{2}{|c|}{ Pemakaian rata-rata } & 5.567 & $1.480)$ \\
\hline
\end{tabular}

Sumber: data Perusahaan Obor Mas (Roti Amin) tahun 2017

Dari tabel 1.1 diatas, dapat terlihat bahwa Perusahaan Obor Mas pada bulan Februari, Maret, Mei, Juni, Juli, dan Oktober pemakaian lebih besar dari pada pembelian, bahan baku yang minim bisa mengakibatkan proses produksi bisa terhambat dan menimbulkan kemacetan operasi. Begitu pula sebaliknya, pada bulan Januari, April, Agustus, September, November dan Desember pemakaian lebih kecil dari pada pembelian. Jika terlalu berlebihan maka yang ada adalah penumpukan bahan baku digudang yang menimbulkan bertambahnya biaya penyimpanan tersebut. Maka dari itu sangat diperlukan metode yang mampu mengendalikan persediaan bahan baku guna melancarkan proses produksi secara berkelanjutan.

Dalam suatu perusahaan, bahan baku adalah sumber utama jalannya produksi. Masalah penentuan besarnya persediaan merupakan masalah yang penting bagi perusahaan, karena persediaan mempunyai efek langsung terhadap keuntungan perusahaan. Adanya persediaan bahan baku terlalu besar dibandingkan dengan kebutuhan perusahaan akan menambah biaya penyimpanan dan kemungkinan terjadinya 
penyusutan dan kualitas yang tidak dapat dipertahankan sehingga akan mengurangi keuntungan perusahaan. Demikian pula sebaliknya, persediaan bahan baku yang terlalu kecil dalam perusahaan akan mengakibatkan kemacetan dalam proses produksi, sehingga perusahaan akan mengalami kerugian.

Sebagaimana dengan paparan tersebut, maka dapat diperoleh beberapa rumusan masalah sebagai berikut: (1) Berapa jumlah pembelian tepung terigu yang optimal dengan menggunakan metode Economic Order Quantity (EOQ) pada perusahaan Obor Mas ?(2)Berapa frekuensi pembelian bahan baku tepung terigu yang optimal dengan menggunakan metode Economic Order Quantity (EOQ) pada perusahaan Obor Mas? (3) Berapa jumlah persediaan pengaman atau Safety Stock bahan baku tepung terigu yang optimal dengan menggunakan metode Economic Order Quantity(EOQ)pada perusahaan Obor Mas ? (4) Berapa jumlah Reorder Point persediaan bahan baku dengan menggunakan metode Economic Order Quantity (EOQ) pada perusahaan Obor Mas? (5) Berapa besar total biaya persediaan atau Total Inventory Cost jika menggunakan metode Economic Order Quantity (EOQ) pada perusahaan Obor Mas ? (6) Bagaimanakah analisis perbandingan perhitungan persediaan bahan baku antara metode Economic Order Quantity (EOQ) dengan perhitungan perusahaan?

Adapun penelitian ini dilakukan dengan tujuan untuk dapat menetapkan atau menghitung jumlah pembelian tepung terigu yang optimal. Tujuan lainnya yaitu untuk dapat menetapkan atau menghitung frekuensi pembelian yang seharusnya dilakukan oleh perusahaan, untuk dapat menetapkan atau menghitung jumlah persediaan pengaman (Safety Stock) yang seharusnya disediakan oleh perusahaan, dan untuk menetapkan atau menghitung kapan seharusnya perusahaaan melakukan pemesanan kembali bahan baku (Reorder Point). Selain itu, untuk dapat menetapkan atau menghitung biaya total persediaan (Total Inventory Cost) yang seharusnya dikeluarkan oleh perusahaan Obor Mas Roti Amin Bandar Lampung.

\section{Tinjauan Pustaka}

ManajemenMenurut Malayu S.P. Hasibuan (2013:1)Mengemukakan bahwa manajemen adalah ilmu dan seni mengatur proses pemanfaatan sumber daya manusia dan sumber-sumber daya lainnya secara efektif dan efisien untuk mencapai suatu tujuan tertentu.

\section{Pengertian Manajemen Operasional}

Menurut Heizer dan Render (2015:11) manajemen operasional adalah aktivitas yang menciptakan nilai dalam bentuk barang dan jasa dengan mengubah input menjadi output. Menurut Murdifin dan Mahmud (2017:14) edisi 3, sasaran yang hendak dicapai manajemen operasional ialah mewujudkan efisiensi ekonomi (cost minimization) dalam proses produksi, baik barang maupun jasa, kualitas yang tinggi (high quality), dapat diserahkan kepasar dalam waktu yang cepat (speed of delivery), dan peralatan produksi dapat dengan segera diahlikan untuk mengerjakan produk lainnya (flexibility). Dengan demikian manajemen operasional mengkaji tentang produksi barang dan jasa.

Pengendalian Persediaan, Menurut Sondang P. Siagian dalam buku Nanang Fattah (2007:176) menjelaskan bahwa : "Pengendalian adalah proses pengamatan dari pada pelaksanaan seluruh kegiatan organisasi untuk menjamin agar semua pekerjaan yang sedang dilakukan berjalan sesuai dengan rencana yang telah ditetapkan". Persediaan merupakan komponen yang terpenting di perusahaan.Deltiana (2011) mengatakan bahwa "persediaan merupakan salah satu asset yang sangat mahal dalam suatu perusahaan (biasanya sekitar $40 \%$ dari total investasi)".Bila perusahaan menanamkan terlalu banyak dananya dalam persediaan, menyebabkan biaya penyimpanan yang berlebih, dan mungkin mempunyai opportunity cost ( dana dapat ditanamkan dalam investasi yang lebih menguntungkan). Demikian pula, bila perusahaan tidak memiliki persediaan yang cukup, dapat mengakibatkan biaya-biaya dan terjadinya kekurangan bahan.

Faktor - Faktor yang Mempengaruhi Persediaan, menurut Nafirin (2014:88) adalah :1) Anggaran Produksi 2) Harga beli bahan baku3) Biaya penyimpanan bahan baku digudang (carring cost) : 4) Ketepatan Pembuatan Standar Pemakaian Bahan Baku 5) Ketepatan Pemasok (Penjual Bahan Baku) 6) Jumlah Bahan Baku Setiap Kali Pesan. 
Biaya Persediaan, Menurut Deltiana (2011) masalah utama yang ingin dicapai oleh pengendalian persediaan adalah meminimumkan biaya operasi total perusahaan.Jadi ada dua keputusan yang perlu diambil dalam hal ini, yaitu berapa jumlah yang harus dipesan setiap kali pemesanan, dan kapan pemesanan itu harus dilakukan.Menurut Murdifin dan mahfud (2017:10) edisi 3, biaya - biaya persediaan terdiri atas biaya variabel dan biaya tetap.Biaya variabel persediaan meliputi sebagai berikut.1) Ordering Cost, yaitu pemesanan yang meliputi biaya - biaya menunggu permintaan pembelian, penyampaian pesanan pembelian, dan yang berhubungan dengan biaya akuntansi dan juga biaya penerimaan dan pemeriksaan pesanan.

2) Storage or holding, or carrying cost adalah biaya atas sediaan yang terjadi jadi sehubungan dengan dipeliharanya sejumlah sediaan tertentu dalam perusahaan.

Economic Order Quantity (EOQ), Salah satu model untuk mengontrol model persediaan adalah dengan Economic Order Quantity (EOQ).Heizer dan Render (2010:92) menerangkan bahwa Economic Order Quantity (EOQ) merupakan sebuah teknik kontrol persediaan yang meminimalkan biaya total dari pemesanan dan penyimpanan. Pengadaan persediaan oleh perusahaan sangat penting guna kelancaran proses produksi. Untuk mendapatkan besarnya pembeliaan yang optimal setiap kali pesan dengan biaya minimal menurut Suryono dan Suhendar (2013) Formula dasar dari model EOQ adalah sebagai berikut $\mathrm{EOQ}=\sqrt{ }$

Keterangan $=\mathrm{D}:$ pemakaian bahan periode waktu. S : biaya pemesanan per pesanan. $\mathrm{H}$ : biaya penyimpanan per unit per tahun.

Asumsi Economic Order Quantity(EOQ), Menurut Deltiana (2011) asumsi yang perlu ada pada saat mengaplikasikan EOQ model adalah : 1) Kebutuhan (Q) diketahui dan bersifat konstan dalam suatu periode perencanaan. 2) Lead time (LT) atau waktu menunggu kedatangan barang/bahan diketahui dan konstan. 3) Penerimaan barang/bahan yang dipesan bersifat instan, 4) Tidak ada quantity discount, 5) Biaya variable hanya terdiri dari atas; set-up cost dan holding cost. Stock-out harus dihindari dengan menjaga kedatangan barang/bahan yang tepat waktu.

\section{Persediaan Pengaman (Safety stock),} Menurut Kosasih (2009) safety stock (persediaan pengaman) adalah persediaan yang dipertahankan untuk menghadapi kondisi yang tidak diharapkan yang timbul secara tidak terduga. Kondisi yang tidak terduga antara lain : 1)Kiriman dari supplier telat (tidak sesuai lead time) padahal persediaan sudah habis. 2) Kiriman dari supplier tepat pada waktunya tetapi jumlahnya tidak memadai.3) Kiriman dari supplier tepat pada waktunya dan jumlahnya sesuai dengan permintaan, tetapi kualitasnya tidak sesuai dengan standar.3) Kiriman dari supplier sesuai dengan waktu, kualitas, dan kuantitas tapi tiba-tiba penggunaan bahan meningkat karena meningkatnya permintaan customer.4)Terjadi kerusakan pada salah satu mesin produksi padahal produksi harus sesuai dengan jadwal.5)Terjadi permintaan yang mendadak dari konsumen padahal proses produksinya tidak bisa dilakukan saat itu.Berdasarkan paparan diatas, maka dapat disimpulkan bahwa safety stock adalah persediaan bahan minimum yang harus dimilki oleh perusahaan untuk menjaga terjadinya keterlambatan agar tidak menggangu kelancaran produksi.

$$
\text { Safety stock }=(
$$

\section{)}

Titik Pemesanan Kembali atau Reorder Point (ROP), Reorder Point memerhatikan pada persediaan yang tersisa digudang baru kemudian dilakukan pemesanan kembali. Hal ini dikarenakan adanya jangka waktu tunggu diantara pemesanan dengan datangnya pesanan, oleh karena itu pemakaian bahan selama pemesanan harus diperhitungkan. Menurut Gasperz (2012) pada dasarnya metode ROP merupakan suatu teknik pengisian kembali inventory apabila total stock on-hand plus on-order jatuh atau berada dibawah titik pemesanan kembali.ROP merupakan metode inventory yang menempatkan suatu pesanan untuk lot tertentu apabila kualitas on-hand berkurang sampai tingkat yang ditentukan terlebih dahulu yang dikenal sebagai titik pemesanan kembali (ROP). Reorder point berdasarkan paparan Slamet (2007:72) diformulasikan sebagai berikut:

$$
\text { Reorder Point }=(\text { ) }
$$

Keterangan $=$ LD :Lead Time atau waktu tunggu. AU :Average Unit atau rata-rata 
pemakaian selama satuan waktu. SS : Safety stock atau persediaan pengaman.

Total Biaya Persediaan atau Total Inventory Cost (TIC), Total biaya persediaan meliputi penjumlahan dari biaya pemesanan ditambah biaya penyimpanan, ditambah harga dari bahan itu sendiri. Rumus biaya persediaan total menurut Handoko (2015:343) :

$$
\text { TIC = †] [ ] - }
$$

Keterangan $=\mathrm{D}$ : jumlah kebutuhan barang dalam unit. $\mathrm{S}$ : biaya pemesanan setiap kali pesan. H: biaya penyimpanan.

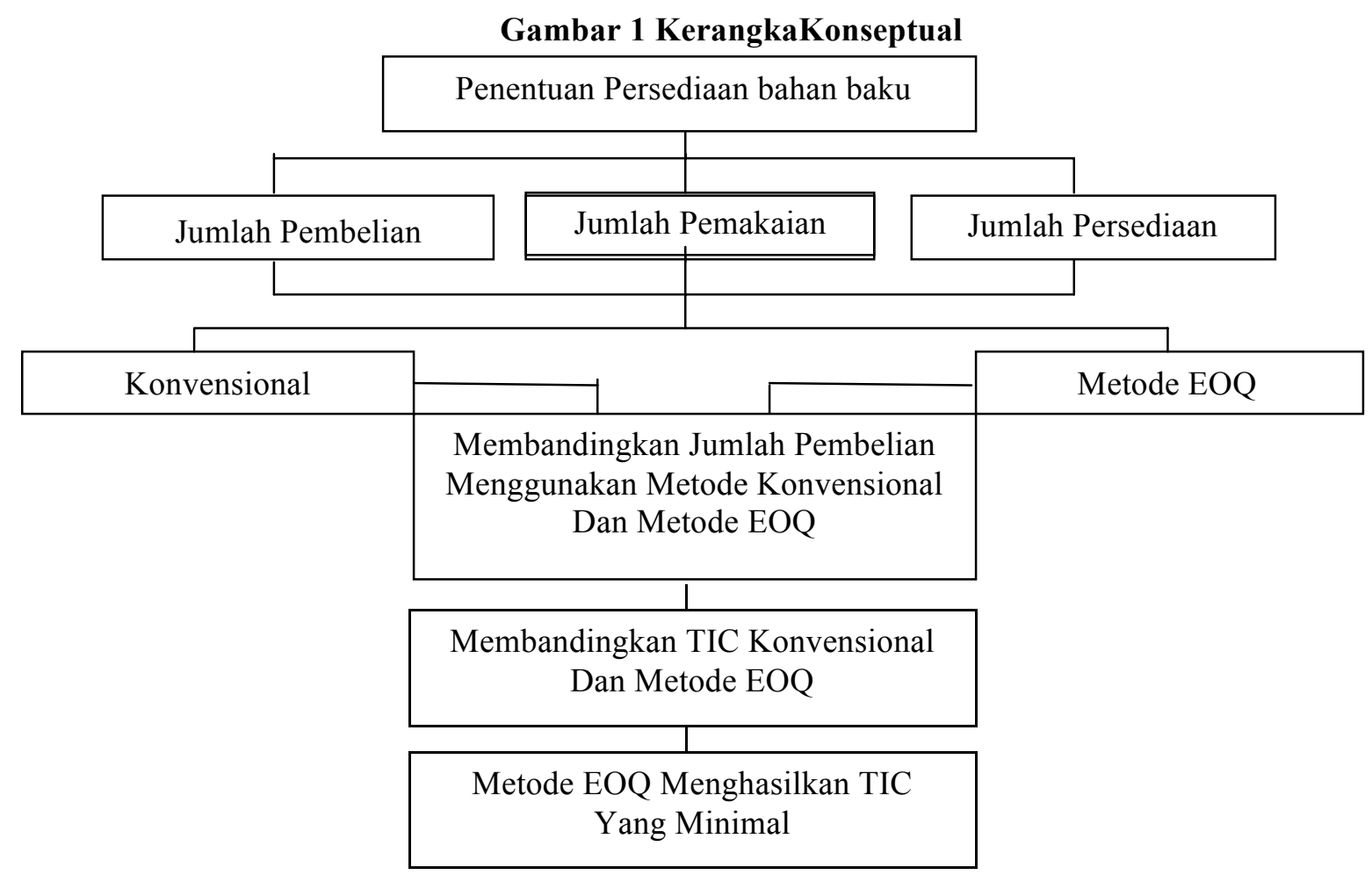

Sumber: Jay Heizer \& Barry Render (2010:2012)"Manejemen Operasi"

\section{METODE PENELITIAN}

Jenis Penelitian Jenis penelitian yang digunakan peneliti adalah penelitiankuantitatif.Dengan menggunakan desain berupa penelitian penelusuran.Dalam penelitian ini, metode yang digunakan terhadap Perusahaan Obor Mas Bandar Lampung adalah Economic Order Quantity (EOQ) untuk mengukur angka persediaan yang optimal.

Desain Penelitian, Penelitian ini merupakan penelitian kuantitatif dengan mengolah data dengan rumus - rumus statistik yang disediakan, baik secara manual maupun dengan menggunakan jasa komputer.

Teknik Pengumpulan Data, Adapun teknik pengumpulan data dalam penelitian ini adalah sebagai berikut: 1) Observasi data : Observasi merupakan teknik pengumpulan data yang dilakukan dengan mengadakan pengamatan secara langsung terhadap objek penelitian. 2)Wawancara :merupakan teknik pengumpulan data yang dilakukan langsung melalui tanya jawab dengan responden dan pihak-pihak yang berkaitan dalam penelitian ini. Teknik pengumpulan data dilakukan dengan cara bertemu langsung face to face antara peneliti dengan pemberi informasi secara terstruktur. Artinya, peneliti sudah terlebih dahulu membuat konsep pertanyaan yang sesuai dengan penelitian ini yang dapat dijawab oleh pemberi informasi. 3) Dokumentasi :Dalam teknik dokumentasi peneliti mengumpulkan data-data yang dilakukan dengan caramencari data berupa laporan persediaan barang pada Perusahaan Obor Mas (Roti Amin) Bandar Lampung. 
Jenis dan Sumber Data, Jenis data yang digunakan dalam penelitian ini adalah termasuk data primer dan data sekunder.Data primer adalah data yang diperoleh dengan melakukan wawancara dan observasi, dari sumbernya.Sumber data ini adalah sumber data eksteranal, yaitu diperoleh dari observasi dan wawancara langsung dari owner perusahaan Obor Mas Bandar Lampung.Sedangkan data sekunder adalah data yang diperoleh dari pihak kedua atau yang tidak perlu diolah kembali. Sumber data ini adalah sumber data internal, yaitu diperoleh dari perusahaan Obor Mas Bandar Lampung berupa data pembelian bahan baku, data pemakaian bahan baku dan biaya-biaya yang dikeluarkan pada saat melakukan pembelian bahan baku.

\section{HASIL DAN PEMBAHASAN}

Metode Analisis Data, Metode analisis data yang digunakan dalam penelitian ini merupakan metode deskriptif kuantitatif dengan mengolah data dengan rumus - rumus stastistik yang disediakan, baik secara manual maupun dengan menggunakan jasa computer. Setelah data terkumpul peneliti melakukan identifikasi pada produk kemudian dilakukan perhitungan yang menggunakan metode EOQ (Economic Order Quantity) digunakan untuk mencari pemesanan yang ekonomis pada suatu barang dalam satu tahun agar perusahaan tidak kekurangan stock ataupun kelebihan stock. Safety stock digunakan untuk mencari persediaan pengaman pada suatu produk dan reorder point merupakan perhitungan untuk menentukan titik pemesanan kembali, ketika persediaan telah mencapai titik tersebut maka dilakukan pemesanan barang.

\section{Persediaan Bahan Baku Tepung Terigu Menurut Kebijakan Perusahaan Obor Mas ( Roti Amin ) Bandar Lampung.}

Tabel 2 Kuantitas dan Tingkat Persediaan Rata-Rata Bahan Baku Tepung Terigu pada Perusahaan Obor Mas Bandar Lampung Tahun 2017

\begin{tabular}{|l|r|r|r|r|r|r|}
\hline \multicolumn{1}{|c|}{ Bulan } & $\begin{array}{r}\text { Persediaan } \\
\text { Awal (Kg) }\end{array}$ & $\begin{array}{c}\text { Pembelian } \\
(\mathrm{Kg})\end{array}$ & $\begin{array}{c}\text { Total Persediaan } \\
\text { Awal (Kg) }\end{array}$ & $\begin{array}{c}\text { Pemakaian } \\
(\mathrm{Kg})\end{array}$ & $\begin{array}{c}\text { Total } \\
\text { Persediaan } \\
\text { Akhir (Kg) }\end{array}$ & $\begin{array}{c}\text { Persediaan } \\
\text { Rata-Rata } \\
(\mathrm{Kg})\end{array}$ \\
\hline Januari & 400 & 5.800 & 6.200 & 4.040 & 1.160 & 6.780 \\
\hline Februari & 1.160 & 5.200 & 6.360 & 5.400 & 960 & 6.840 \\
\hline Maret & 960 & 5.400 & 6.360 & 5.760 & 600 & 6.660 \\
\hline April & 600 & 5.700 & 6.300 & 4.320 & 1.980 & 7.290 \\
\hline Mei & 1.980 & 5.200 & 7.180 & 5.400 & 1.780 & 8.070 \\
\hline Juni & 1.780 & 5.400 & 7.180 & 6.120 & 1.060 & 7.710 \\
\hline Juli & 1.060 & 5.900 & 6.960 & 6.840 & 120 & 7.020 \\
\hline Agustus & 120 & 5.900 & 6.020 & 5.760 & 260 & 6.150 \\
\hline September & 260 & 5.900 & 6.160 & 4.680 & 1.480 & 6.900 \\
\hline Oktober & 1.480 & 5.000 & 6.480 & 6.480 & 0 & 6.480 \\
\hline November & 0 & 5.600 & 5.600 & 5.400 & 200 & 5.700 \\
\hline Desember & 200 & 5.800 & 6.000 & 5.400 & 600 & 6.300 \\
\hline Total & 10.000 & 66.800 & 76.800 & 66.600 & 10.200 & 81.900 \\
\hline Rata-rata & 833 & 5567 & 6.400 & 5.550 & 850 & 6.825 \\
\hline
\end{tabular}

Sumber :Data diolah tahun 2019

Berdasarkan informasi dari Tabel 4.1 Pembelian Bahan Baku Tepung Terigu Perusahaan Obor Mas dapat diketahui jumlah total pembelian selama satu tahun yaitu sebesar $66.800 \mathrm{~kg}$ dengan rata-rata pembelian $5.567 \mathrm{~kg}$ perbulan. Sedangkan Pemakaian bahan baku tepung terigu Perusahaan Obor
Masa diketahui Jumlah total sebesar $66.600 \mathrm{~kg}$ dengan rata-rata $5.550 \mathrm{~kg}$ perbulannya. Dan diketahui tingkat persediaan rata-rata tiap bulannya sebesar $81.900 \mathrm{~kg}$ dengan rata-rata $6.825 \mathrm{~kg}$ perbulan. 
Tabel 3 Kuantitas dan Frekuensi Pembelian Bahan Baku Tepung Terigu pada Perusahaan Obor Mas Bandar Lampung Tahun 2017

\begin{tabular}{|c|c|c|c|}
\hline Tahun & $\begin{array}{c}\text { Kuantitas Pemesanan Per } \\
\text { Pemesanan }(\mathrm{kg})\end{array}$ & $\begin{array}{c}\text { Frekuensi } \\
(\text { kali })\end{array}$ & $\begin{array}{c}\text { Total Pemesanan } \\
\text { TepungTerigu (kg) }\end{array}$ \\
\hline 2017 & 1.392 & 48 & 66.800 \\
\hline
\end{tabular}

Sumber : Data diolah tahun 2019

Berdasarkan tabel 4.2 diatas dapat diketahui bahwa kuantitas pemesanan rata-rata tepung terigu, frekuensi pemesanan dan total pemesanan tepung terigu pada tahun 2017 , masing - masing yaitu $1.392 \mathrm{~kg}, 48$ kali untuk frekuensi pemesanan dan $66.800 \mathrm{~kg}$ untuk pemesanan tepung terigu.

Tabel 4 Harga Persediaan Bahan Baku Tepung Terigu Pada Perusahaan Obor Mas Tahun 2017

\begin{tabular}{|c|c|c|}
\hline Tahun & Bahan Baku & Harga $(\mathrm{Rp} / \mathrm{Kg})$ \\
\hline 2017 & Tepung terigu & 6.800 \\
\hline
\end{tabular}

Sumber :Data diolah tahun 2019

Tabel 5 Biaya Pemesanan Bahan Baku Tepung Terigu pada Perusahaan Obor Mas Bandar Lampung Tahun 2017

\begin{tabular}{|l|c|c|c|c|}
\hline No & JenisBiaya & Jumlah & Frekuensi Pemesanan & Biaya Pemesanan Pertahun \\
\hline 1 & Biaya Bongkar & Rp100.000 & 48 kali & Rp4.944.000 \\
\hline 3 & Biaya Telepon & Rp 3.000 & & \\
\hline \multicolumn{2}{|c|}{ Jumlah } & Rp103.000 & & \\
\hline
\end{tabular}

Sumber :Data diolah tahun 2019

Terlihat dari tabel 4.4 diatas, bahwa biaya pemesanan per pesanan tahun 2017 yaitu sebesar Rp 103.000,.Diantara kedua biaya yaitu biaya bongkar dan biaya telepon, yang terbesar adalah biaya bongkar yaitu sebesar Rp 100.000,.per pesanan sedangkan biaya telepon yaitu sebesar Rp 3.000,. per pesanan. Frekuensi pemesanan perusahaan sebesar 48 kali, karena dalam pembelian bahan baku mencapai 4 kali dalam satu bulan pada Perusahaan Obor Mas Bandar Lampung. Biaya pemesanan pertahun diperoleh dari perkalian jumlah biaya pemesanan perunit dikali dengan jumlah frekuensi dalam satu tahun sehingga didapat biaya pemesanan pertahun sebesar Rp 4.944.000,.

Tabel 6 Biaya Penyimpanan Bahan Baku Tepung Terigu pada Perusahaan Obor Mas (Roti Amin) Bandar Lampung Tahun 2017

\begin{tabular}{|l|c|c|c|}
\hline \multicolumn{1}{|c|}{ JenisBiaya } & $\begin{array}{c}\text { Harga } \\
(\mathrm{Rp} / \mathrm{kg})\end{array}$ & $\begin{array}{c}\text { Persediaan rata- } \\
\text { rata Pertahun } \\
(\mathrm{Kg})\end{array}$ & $\begin{array}{c}\text { Biaya Penyimpanan } \\
\text { Pertahun }\end{array}$ \\
\hline Biaya Penyusutan Gudang & $\mathrm{Rp} \mathrm{1.318,.}$ & \multirow{2}{*}{$6.825 \mathrm{~kg}$} & $\mathrm{Rp} \mathrm{9.630.075}$ \\
\hline Biaya Listrik & $\mathrm{Rp} \mathrm{93}$ & & \\
\hline Total & $\mathrm{Rp} \mathrm{1.411}$ & & \\
\hline
\end{tabular}

Sumber :Data yang telah diolah tahun 2019

Berdasarkan tabel 4.5 bahwa biaya penyimpanan bahan baku pada Peusahaan Obor Mas Bandar Lampung sebesar Rp 1.411,.persediaan rata-rata pertahun perusahaan dapat dilihat pada tabel 4.1 yaitu sebesar $6.825 \mathrm{~kg}$. Biaya penyimpanan bahan baku pertahun sebesar Rp 9.630.075, yaitu diperoleh dari total biayapenyimpanan per unit dikali dengan persediaan rata-rata pertahun pada perusahaan Obor Mas Bandar Lampung. 


\section{Analisis Persediaan Bahan Baku Tepung Terigu dengan Metode EOQ (Economic Order}

Quantity.

Tabel 7 Perhitungan Kuantitas Pemesanan Optimal Bahan Baku Tepung Terigu pada Perusahaan Obor Mas Bandar Lampung Tahun 2017

\begin{tabular}{|c|c|c|c|c|}
\hline Bahan Baku & $\begin{array}{c}\text { Permintaan } \\
(\mathrm{D})\end{array}$ & $\begin{array}{c}\text { Biaya Pesanan } \\
(\mathrm{S})\end{array}$ & $\begin{array}{c}\text { Biaya Simpanan } \\
(\mathrm{H})\end{array}$ & $\begin{array}{c}\frac{\mathrm{EOQ}\left(\mathrm{Q}^{*}\right)}{\sqrt{ }} \\
\text { Tepung Terigu }\end{array}$ \\
\hline
\end{tabular}

Sumber :Data diolah tahun 2019

Tabel 8 Perhitungan Frekuensi Pemesanan Optimal Bahan Baku Tepung Terigu pada Perusahaan Obor Mas Bandar Lampung Tahun 2017

\begin{tabular}{|l|c|c|c|}
\hline Bahan Baku & $\begin{array}{c}\text { Permintaan } \\
(\mathrm{D})\end{array}$ & $\begin{array}{c}\text { EOQ } \\
\left(\mathrm{Q}^{*}\right)\end{array}$ & $\begin{array}{c}\text { Frekuensi (I) } \\
\end{array}$ \\
\hline Tepung Terigu & $66.600 \mathrm{~kg}$ & $3.118 \mathrm{~kg}$ & $21 \mathrm{kali}$ \\
\hline
\end{tabular}

Sumber :Data diolah tahun 2019

Berdasarkan tabel 4.7 diatas bahwa frekuensi pemesanan bahan baku tepung terigu berdasarkan metode EOQ lebih sedikit bila dibandingkan dengan frekuensi pemesanan yang telah dilakukan berdasarkan metode perusahaan. Frekuensi pemesanan bahan baku tepung terigu dengan metode perusahaan dilakukan sebanyak 48 kali pemesanan dalam setahun, sedangkan pemesanan dengan metode EOQ dilakukan sebanyak 21 kali dalam setahun.

Hasil penelitian dan analisis kuantitas pemesanan bahan baku tepung terigu pada Perusahaan Obor Mas dengan metode EOQ (Economic Order Quantity) menunjukan kuantitas pemesanan bahan baku menjadi lebih besar yaitu $3.118 \mathrm{~kg}$ dan frekuensi pemesanan lebih rendah yaitu sebanyak 21 kali.

Tabel 9 Perhitungan Safety Stock Bahan Baku Tepung Terigu pada Perusahaan Obor Mas Bandar Lampung Tahun 2017

\begin{tabular}{|c|c|c|c|c|}
\hline Bahan Baku & $\begin{array}{c}\text { PemakaianMaksimum } \\
(\text { MAX })\end{array}$ & $\begin{array}{c}\text { Pemakaian Rata }- \\
\text { Rata } \\
(\text { AU })\end{array}$ & $\begin{array}{c}\text { Leadtime } \\
(\text { LD })\end{array}$ & $\begin{array}{c}\text { Safety Stock } \\
\text { SS = (MAX-AU) } \\
\text { LD }\end{array}$ \\
\hline TepungTerigu & $6.840 \mathrm{~kg}$ & $5.550 \mathrm{~kg}$ & 1 hari & $1.290 \mathrm{~kg}$ \\
\hline
\end{tabular}

Sumber :Data diolah tahun 2019

Tabel 10 Perhitungan Reorder Point Bahan Baku Tepung Terigu pada Perusahaan Obor Mas Bandar Lampung Tahun 2017

\begin{tabular}{|l|c|c|c|c|}
\hline Bahan Baku & $\begin{array}{c}\text { Leadtime } \\
(\mathrm{LD})\end{array}$ & $\begin{array}{c}\text { Pemakaian Rata- } \\
\text { Rata Perhari } \\
\text { (AU) }\end{array}$ & $\begin{array}{c}\text { Safety Stock } \\
(\mathrm{SS})\end{array}$ & $\begin{array}{c}\text { Reorder Point } \\
\mathrm{ROP}=(\mathrm{)})\end{array}$ \\
\hline TepungTerigu & 1 hari & $231 \mathrm{~kg}$ & $1.290 \mathrm{~kg}$ & $1.521 \mathrm{~kg}$ \\
\hline
\end{tabular}

Sumber :Data diolah tahun 2019 
Gambar 2 Grafik Pemakaian dan Pemesanan Menggunakan Metode EOQ

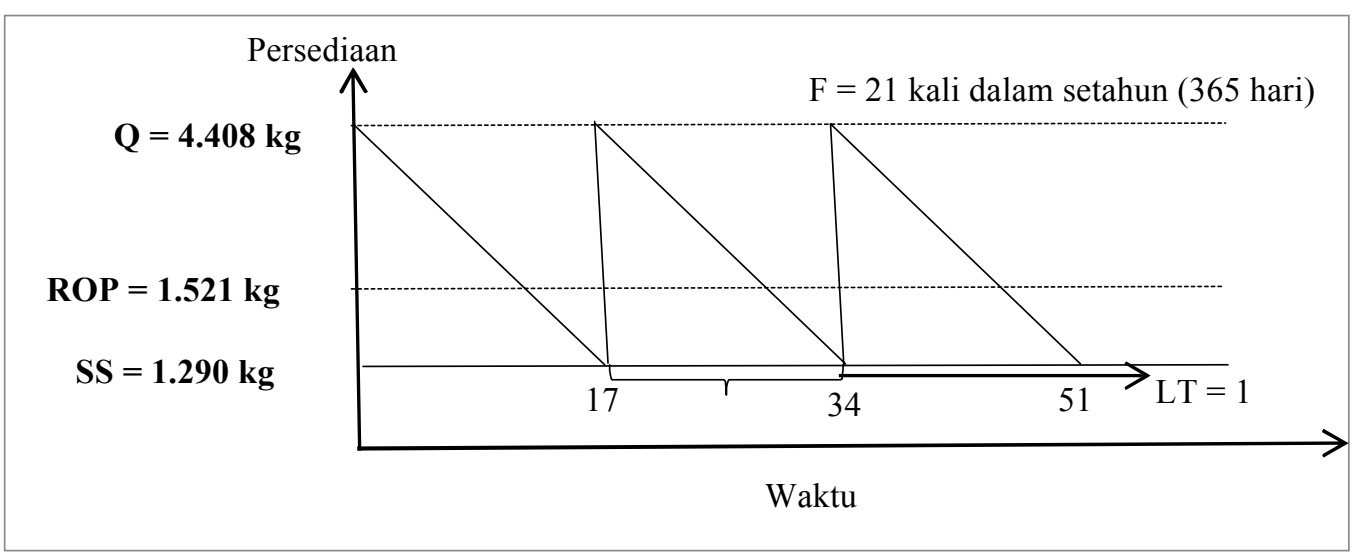

Sumber :Data diolah tahun 2019

Berdasarkan grafik jumlah pembelian dengan menggunakan Metode Economic Order Quantity (EOQ) yaitu sebesar 3.118 $\mathrm{kg}$ dengan frekuensi 21 kali dalam setahun atau 17 hari sekali.Jumlah persediaan pengaman (safety stock) yaitu sebesar 1.290

kg.Perusahaan melakukan pemesanan kembali (reorder point) pada saat persediaan mencapai $1.521 \mathrm{~kg}$.Q sebesar $4.408 \mathrm{~kg}$ didapat dari EOQ sebesar $3.118 \mathrm{~kg}$ ditambah dengan safety stock sebesar $1.290 \mathrm{~kg}$.

\section{Tabel 11 Perhitungan Total Inventory Cost Bahan Baku Tepung Terigu Menggunakan EOQ} pada Perusahaan Obor Mas Bandar Lampung Tahun 2017

\begin{tabular}{|c|c|c|c|c|}
\hline Bahan Baku & $\begin{array}{l}\text { Frekuensi } \\
\text { A }\end{array}$ & $\begin{array}{c}\text { KuantitasPemesanan } \\
(\mathrm{Q} / 2) \\
\text { B }\end{array}$ & $\begin{array}{c}\text { BiayaPesanan/Pesan } \\
\text { (S) } \\
\text { c }\end{array}$ & $\begin{array}{c}\text { BiayaSimpan } / \mathrm{kg} / \text { tahun } \\
(\mathrm{H}) \\
\mathbf{d}\end{array}$ \\
\hline TepungTerigu & 21 kali & $1.163 \mathrm{~kg}$ & Rp 103.000 & $\mathrm{Rp} 1.411$ \\
\hline
\end{tabular}

Sumber : Data diolah tahun 2019

\begin{tabular}{|c|c|c|c|}
\hline Bahan Baku & $\begin{array}{c}\text { BiayaPesanan/ } \\
\text { Tahun } \\
\mathbf{e}=\mathbf{a ~ c}\end{array}$ & $\begin{array}{c}\text { BiayaSimpanan/Tahun } \\
\mathbf{f = b ~ d}\end{array}$ & $\begin{array}{c}\text { Total } \\
\text { BiayaPersediaan } \\
\mathbf{e}+\mathbf{f}\end{array}$ \\
\hline TepungTerigu & $\mathrm{Rp} 2.163 .000$ & $\mathrm{Rp} \mathrm{1.640.993}$ & $\mathrm{Rp} \mathrm{3.803.993}$ \\
\hline
\end{tabular}

Sumber :Data diolah tahun 2019

3. Analisis Perbandingan Perhitungan Perusahaan dengan Metode Economic Order Quantity (EOQ)

Tabel 12 Perbandingan Kuantitas dan Frekuensi Pemesanan Bahan Baku antara Kebijakan Perusahaan dengan Metode EOQ pada Perusahaan Obor Mas (Roti Amin) Bandar Lampung Tahun 2017

\begin{tabular}{|c|c|c|c|c|c|c|}
\hline $\begin{array}{c}\text { PersediaanBahan } \\
\text { Baku }\end{array}$ & \multicolumn{2}{|c|}{ Kebijakan Perusahaan } & \multicolumn{2}{c|}{ Metode EOQ } & \multicolumn{2}{c|}{ Selisih } \\
\cline { 2 - 7 } & $\begin{array}{c}\mathrm{Q} \\
(\mathrm{kg})\end{array}$ & $\begin{array}{c}\text { Frek } \\
(\mathrm{kali})\end{array}$ & $\begin{array}{c}\mathrm{Q} \\
(\mathrm{Kg})\end{array}$ & $\begin{array}{c}\text { Frek } \\
(\mathrm{kali})\end{array}$ & $\begin{array}{c}\mathrm{Q} \\
(\mathrm{kg})\end{array}$ & $\begin{array}{c}\text { Frek } \\
(\mathrm{kali})\end{array}$ \\
\hline TepungTerigu & 1.392 & 48 & 3.118 & 21 & 1.726 & 27 \\
\hline
\end{tabular}

Sumber : Perusahaan Obor Mas (Roti Amin) Bandar Lampung yang telah diolah..

Tabel 13 Perbandingan Safety Stock Bahan Baku antara Kebijakan Perusahaan dengan Metode EOQ pada Perusahaan Obor Mas (Roti Amin) Bandar Lampung Tahun 2017

\begin{tabular}{|c|c|c|c|}
\hline \multirow{2}{*}{$\begin{array}{c}\text { Persediaan Bahan } \\
\text { Baku }\end{array}$} & \multicolumn{2}{|c|}{ Safety Stock } & Selisih Efisien \\
\cline { 2 - 3 } & $\begin{array}{c}\text { Kebijakan } \\
\text { Perusahaan }\end{array}$ & $\begin{array}{c}\text { Metode EOQ } \\
(\mathrm{kg})\end{array}$ & $(\mathrm{kg})$ \\
\hline TepungTerigu & Tidak Ada & 1.290 & 1.290 \\
\hline
\end{tabular}

Sumber : Perusahaan Obor Mas (Roti Amin) Bandar Lampung yang telah diolah 
Tabel 14 Perbandingan Reorder Point Bahan Baku antara Kebijakan Perusahaan dengan Metode EOQ pada Perusahaan Obor Mas (Roti Amin) Bandar Lampung Tahun 2017

\begin{tabular}{|c|c|c|c|}
\hline \multirow{2}{*}{$\begin{array}{c}\text { PersediaanBahan } \\
\text { Baku }\end{array}$} & \multicolumn{2}{|c|}{ Reorder Point } & SelisihEfisien \\
\cline { 2 - 3 } & $\begin{array}{c}\text { Kebijakan } \\
\text { Perusahaan }\end{array}$ & $\begin{array}{c}\text { Metode EOQ } \\
(\mathrm{kg})\end{array}$ & $(\mathrm{kg})$ \\
\hline TepungTerigu & Tidak Ada & 1.521 & 1.521 \\
\hline
\end{tabular}

Sumber :Data yang telah diolah tahun 2019

Tabel. 15 Perbandingan Total Inventory Cost (TIC)Bahan Baku antara Kebijakan Perusahaan dengan Metode EOQ pada Perusahaan Obor Mas (Roti Amin) Bandar Lampung Tahun 2017.

\begin{tabular}{|l|c|c|c|}
\hline \multicolumn{1}{|c|}{ Kategori } & $\begin{array}{c}\text { Kebijakan } \\
\text { Perusahaan }(\mathrm{Rp})\end{array}$ & $\begin{array}{c}\text { Metode EOQ } \\
(\mathrm{Rp})\end{array}$ & $\begin{array}{c}\text { SelisihEfisien } \\
\mathrm{Rp}\end{array}$ \\
\hline BiayaPemesanan & 4.944 .000 & 2.163 .000 & 2.781 .000 \\
\hline BiayaPenyimpanan & 9.630 .075 & 1.640 .993 & 7.989 .082 \\
\hline BiayaPersediaan & 14.574 .075 & 3.803 .993 & 10.770 .082 \\
\hline
\end{tabular}

Sumber :Data yang telah diolah tahun 2019

\section{KESIMPULAN DAN SARAN Kesimpulan}

Berdasarkan hasil penelitian dapat diperoleh kesimpulan bahwa metode metode EOQ (Economic Order Quantity) lebih efisien dibandingkan dengan kebijakan perusahaan. Hal tersebut dibuktikan dengan adanya pembelian yang optimal dan penghematan TIC (Total Inventory Cost)sebagai berikut :

1. Pembelian persediaan bahan baku tepung terigu yang paling optimal dengan metode EOQ (Economic Order Quantity) pada tahun 2017 adalah sebesar $3.118 \mathrm{~kg}$ yaitu dengan frekuensi pembelian sebanyak 21 kali.

2. Jumlah persediaan pengaman atau Safety Stock bahan baku tepung terigu pada perusahaan Obor Mas (Roti Amin) tahun 2017 yang optimal dengan menggunakan metode Economic Order Quantity (EOQ)pada perusahaan Obor Mas Bandar Lampung yaitu sebesar $1.290 \mathrm{~kg}$.

3. Titik pemesanan kembali atau Reorder Pont bahan baku tepung terigu pada perusahaan Obor Mas (Roti Amin) tahun 2017 yang efisien menggunakan metode perhitungan EOQ (Economic Order Quantity) yaitu sebesar $1.521 \mathrm{~kg}$.

4. Perhitungan TIC (Total Inventory Cost) persediaan bahan baku tepung terigu pada perusahaan Obor Mas (Roti Amin) tahun 2017 dengan menggunakan metode EOQ yaitu sebesar Rp3.803.993, .
5. Pembelian bahan baku yang dilakukan oleh perusahaan cenderung tidak efisien karena biaya total persediaan menurut kebijakan perusahaan lebih besar dibandingkan dengan biaya total persediaan menggunakan metode EOQ (Economic Order Quantity). Apabila perusahaan menerapkan metode EOQ (Economic Order Quantity), maka pada tahun 2017 perusahaan dapat melakukan pengematan biaya total persediaan bahan baku sebesar Rp10.770.082,. Berarti dengan menggunakan metode EOQ (Economic Order Quantity) perusahaan dapat melakukan pengehematan biaya total persediaan bahan baku yang cukup besar dibandingkan dengan menggunakan kebijakan perusahaan. Kondisi tersebut membuktikan bahwa metode EOQ (Economic Order Quantity) dapat mengefesiensi biaya-biaya persediaan sehingga perusahaan dapat memaksimalkan keuntungan.

\section{Saran}

Berdasarkan kesimpulan diatas, maka penelitian dapat memberikan saran kepada perusahaan yang dapat digunakan sebagai bahan pertimbangan adalah perusahaan sebaiknya meninjau kembali kebijakn persediaan bahan baku yang selama ini telah dilakukan perusahaan, yaitu :

1. Bagi perusahaan Obor Mas (Roti Amin) Bandar Lampung dalam penerapan 
pengendalian bahan baku sebaiknya menggunakan metode EOQ (Economic order Quantity) dan meninggalkan metode konvensional karena dengan perhitungan metode EOQ (Economic order Quantity) perusahaan dapat mengoptimalkan persediaan dan dapat mengefisiensi biaya persediaan.

2. Bagi perusahaan sebaiknya menentukan besarnya persediaan pengaman (safety stock), pemesanan kembali (Reorder Point) dan persediaan minimum untuk menghindari resiko kehabisan bahan baku (stock out) dan juga kelebihan bahan baku sehingga dapat meminimalisasi biaya bahan baku bagi perusahaan.

\section{DAFTAR PUSTAKA}

Deltiana, Tita. (2011). Manajemen Operasional Strategidan Analisa Service dan Manufaktur.Jakarta: MitraWacanaMedia.

Gaspersz, V. (2012). All-in-one. Production and Inventory Management. Vinchristo Publication. Bogor.

Haming, Murdifin dan Nurnajamuddin, Mahfud. (2017). Manajemen Produksi Modern: Operasi Manufaktur dan Jasa. Buku1.EdisiTiga. Jakarta: PT.Bumi Aksara
Handoko, T,H. (2015). Dasar - Dasar Manajemen Produksi Dan Operasi. Yogyakarta:BPFE.

Heizer, Jay dan Barry, Render.(2010). Operations Management: Manajemen Operasi. Buku2.EdisiKesembilan. Jakarta: SalembaEmpat.

(2015).

Operations Management: Manajemen Operasi. Buku2.EdisiKesebelas. Jakarta: Salemba Empat.

Kosasih, Sobarsa, M. (2009). Manajemen Operasi International. Mitra Wacana Media : Yogyakarta.

Nafarin, M. (2014).Penganggaran Perusahaan. EdisiRevisi. Jakarta: Salemba Empat.

Siagian, Sondang P. (2007). Fungsi-fungsi Manajerial. EdisiRevisi. PT.Bumi Aksara: Jakarta.

Slamet, Achmad. (2007). Penganggaran Perencanaan dan Pengendalian Usaha. Semarang: UNNES PRESS.

Suryono, H. \& Endang Suhendar. (2013). Manajemen Produksi dan Operasi. MitraWacana Media. 
